\title{
Análisis y evaluación de las patologías presentes en la estructura del Teatro Campoamor de La Habana
}

\author{
A. H. Oroza ${ }^{1 *}$, A. Romeo Saéz ${ }^{1}$ P. Braña Nuez ${ }^{1}$, R. Castello Bello ${ }^{1}$ \\ *Autor de Contacto: ahernandez@proyectos.ohc.cu \\ ${ }^{1}$ Departamento de Diagnóstico y Levantamiento, UEB Restaura, Oficina del Historiador de La Habana, La Habana, \\ Cuba
}

\section{RESUMEN}

El Teatro Campoamor se encuentra severamente afectado por diversas causas estructurales, ambientales y antropogénicas, como resultado de décadas de abandono y cambios de uso invasivos.

El presente trabajo tiene como objetivo documentar las lesiones presentes y evaluar, a partir de modelos de elevación con escáner láser, el impacto de estos sobre la obra construida. El diagnóstico realizado permitió identificar como causas principales de deterioro a los procesos de corrosión, degradación de material y crecimiento de plantas superiores.

Los resultados obtenidos demuestran el avanzado deterioro de los elementos estructurales y la necesidad inminente de iniciar acciones de reforzamiento estructural, con el objetivo de preservar un inmueble que formó parte de la vida social y cultural de la nación cubana.

Palabras clave: corrosión, contaminación, conservación, láser escáner.

\section{RESUMO}

O Teatro Campoamor é severamente afetado por várias causas estruturais, ambientais e antropogênicas, como resultado de décadas de abandono e mudanças invasivas de uso.

O objetivo deste trabalho é documentar as lesões presentes e avaliar, a partir de modelos de elevação com scanner a laser, o impacto destas na obra. O diagnóstico realizado permitiu identificar como principais causas de deterioração os processos de corrosão, degradação dos materiais e crescimento das plantas superiores.

Os resultados obtidos demonstram a deterioração avançada dos elementos estruturais e a necessidade iminente de iniciar ações de reforço estrutural, com o objetivo de preservar um patrimônio que fazia parte da vida social e cultural da nação cubana.

Palavras-chave: corrosão, contaminação, conservação, scanner a laser. 


\begin{abstract}
The Campoamor Theater is severely affected by various structural, environmental and anthropogenic causes, as a result of decades of neglect and invasive changes of use.

The objective of this work is to document the injuries present and to evaluate, from elevation models with a laser scanner, the impact of these on the built work. The diagnosis carried out allowed to identify as main causes of deterioration the processes of corrosion, material degradation and growth of higher plants.

The results obtained demonstrate the advanced deterioration of the structural elements and the imminent need to initiate structural reinforcement actions, with the aim of preserving a property that was part of the social and cultural life of the Cuban nation.
\end{abstract}

Keywords: corrosion, contamination, conservation, laser scanner.

\title{
1. INTRODUCCIÓN
}


En edificaciones antiguas, el deterioro de los elementos constructivos representa un riesgo para la conservación histórica y cultural de las naciones (Di Turo et al., 2016). Acciones negativas asociadas a la falta de mantenimiento, descuido y abandono inciden directamente en la vida de servicio de la estructura y pueden conllevar a la imposibilidad de recuperarlo parcial o totalmente. Los informes presentados por el Grupo Intergubernamental sobre Cambio Climático (IPCC, 2014) vienen alertando acerca del riesgo existente en las edificaciones como resultado de las variaciones del clima, y el incremento en los niveles de contaminantes atmosféricos. De igual manera, una amplia cantidad de estudios han demostrado el impacto negativo de estas variables ambientales con los sistemas constructivos y los materiales presentes en las edificaciones patrimoniales, las cuales inciden directamente en el desempeño y durabilidad de las estructuras (Brimblecombe et al., 2011; Cavalagli et al., 2019; Fowler et al., 2020; Kumar and Imam, 2013).

Es debido a estas razones que las investigaciones sobre las obras patrimoniales, deben estar apoyadas desde sus inicios en investigaciones históricas, datos técnicos y el levantamiento visual de las lesiones existentes. De acuerdo con (Paradiso et al., 2020), este enfoque representa el eje principal en todo el proceso cognitivo de identificación detallada de los aspectos estructurales, arquitectónicos, ambientales, y otros que pudieran estar incidiendo en su conservación.

El presente trabajo tiene como objetivo documentar las lesiones existentes en el antiguo Teatro Campoamor, y establecer niveles de degradación que permitan identificar las zonas más vulnerables, con mayor necesidad de intervención. Como parte de los objetivos de la Oficina del Historiador de La Habana en el legado dejado por el Dr. Eusebio Leal, se intenta recuperar este teatro que, en su momento, formó parte importante de la vida cultural y social de la ciudad, encontrándose hoy en estado total de abandono y al término de su vida de servicio, con elevado riesgo de derrumbe.

El mismo fue construido por columnas de hormigón armado y muros de ladrillo y tapial, techo a dos aguas con planchas de fibrocemento. En el caso de las vigas, algunas son de hormigón armado, principalmente en la zona de la platea alta y de perfiles metálicos recubiertos con hormigón en el área de los balcones. Las losas de entrepisos están conformadas generalmente por el sistema hollow tile pero existen locales que presentan losas de hormigón armado. El techo está conformado por cerchas metálicas que sostienen la cubierta ligera a dos aguas con planchas de zinc. Lo componía un vestíbulo, con una escalera al local destinado a oficina en la primera planta. En el interior existió un "balcony" y un segundo piso que ocupaba la tertulia con entrada independiente por la calle Industria, ocupando todo el teatro un área total de $704 \mathrm{~m}^{2}$.

\section{PROCEDIMIENTO}

\subsection{Investigación histórica}

El primitivo Teatro Campoamor inaugurado en 1915 y conocido antes como Teatro Albisu, formaba parte en sus orígenes, del edificio que ocupaba la Asociación de Asturianos de Cuba en la calle San Rafael entre Zulueta y Monserrate, el cual fue destruido por un incendio el 23 de octubre de 1918. Poco después, una vez iniciada la década de 1920, se elaboran los proyectos para su reconstrucción, previa la demolición de las ruinas quedadas por el incendio, entre la parcela de las calles Industria y San José, con el nombre de Teatro Capitolio. Más tarde en el año 1924, pasó a llamarse Teatro Campoamor (Figuras 1 y 2) en honor al famoso poeta español, Ramón de Campoamor.

En él tuvieron lugar espectáculos cinematográficos de tema histórico, aventuras, amor, y magníficos conciertos y puesta en escena de obras de teatro de todo género: dramático, vernáculo, lírico y numerosas revistas musicales. A finales de la década de 1950, paulatinamente fue decayendo su categoría y perdiendo los valores que lo enaltecieron. El teatro fue cerrado al público en 1965 y desde entonces ha sido empleado primeramente como almacén, y en las últimas décadas 
como parqueo de bicicletas y vivienda multifamiliar, hasta su total degradación hace más de una década (Sánchez, 2017).
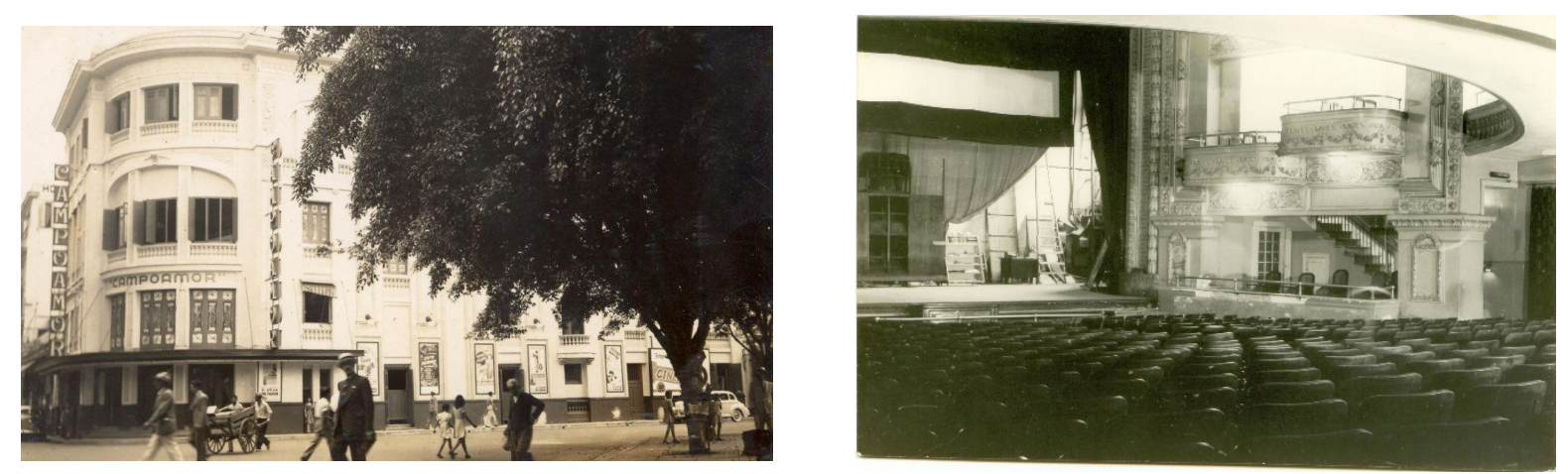

Figuras 1 y 2. Fachada de la entrada principal del Teatro Campoamor en la esquina de las calles Industria y San José (izquierda). Vista del interior del teatro (derecha)

\subsection{Caracterización del ambiente}

La edificación se encuentra ubicada a más de $1 \mathrm{Km}$ de la franja costera norte, adyacente a la calle San José y muy próxima a la avenida de Prado, siendo ambas arterias viales de elevado tráfico vehicular. Las calles aledañas cuentan con autorizo como zonas de parqueo, por lo cual se genera un incremento en los niveles de emisiones por fuentes móviles. Ubicado en un entorno urbano/industrial (ISO-9223, 2012), el mismo se encuentra expuesto a niveles de contaminación atmosférica por compuestos de azufre $\left(\mathrm{SO}_{2}\right)$ entre $21,5-32,7 \mu \mathrm{g} / \mathrm{m}^{3}$, compuesto de nitrógeno (NOx) superiores a $120 \mu \mathrm{g} / \mathrm{m}^{3}$ y niveles de deposición de partículas $\left(\mathrm{PM}_{10}\right)$ por encima de $40 \mu \mathrm{g} / \mathrm{m}^{3}$ (Oroza, 2019; Placeres et al., 2004; Varona et al., 2011). La exposición durante décadas al incremento paulatino y sin regulación de los niveles de emisiones, ha sido la causa principal del ennegrecimiento y la formación de costras negras en amplias zonas de las fachadas, siendo la más afectada la ubicada hacia la calle San José.

\subsection{Metodología de identificación de las lesiones presentes}

Se hace importante destacar que en el inicio de la investigación, se hizo difícil el acceso a todos los espacios interiores, debido al riesgo de colapso de la losa de hormigón armado del segundo nivel, el crecimiento significativo de plantas arbustivas en el interior del teatro y una abrumadora cantidad de escombros. Como resultado de los cambios de uso, los años de abandono y la exposición a un medio de creciente tráfico vehicular se fueron incorporando paulatinamente nuevas formas de deterioro, generando vinculaciones entre sí, como fenómenos de corrosión como resultado de fisuraciones provocadas por las raíces de las plantas superiores, o la erosión y formación de eflorescencias en elementos de piedra como consecuencia de ciclos de humectación y secado.

Con el propósito de emplear una metodología operativa que permitiera mostrar la mayor cantidad de patologías asociadas a diferentes factores: antropogénicos, ambientales, estructurales; se decidió aplicar la metodología propuesta por (ICOMOS-ISCS, 2008). Como método para cuantificar la magnitud de las lesiones, se empleó una escala de 0 a 3, en donde el cero representa un riesgo muy bajo, y 3 un riesgo alto para la conservación de la estructura.

\section{RESULTADOS}

\subsection{Estado de conservación en el interior}


En el teatro Campoamor se evidencia que de manera general la estructura se encuentra severamente deteriorada. La totalidad de los refuerzos de acero, ya sean las barras en del hormigón armado, como perfiles metálicos recubiertos en hormigón hidráulico, están afectados por corrosión atmosférica. En algunos elementos, el avance de este fenómeno ha provocado delaminación y fractura de las barras, fundamentalmente en vigas y losas. El crecimiento de plantas de porte arbóreo es otro de los aspectos más significativos. Especies de árboles como el Laurel de la India (Ficus Benjamina), colonizó casi todos los muros interiores, generando una importante cantidad de grietas y desprendimiento de material durante su crecimiento. También se identificaron una importante cantidad de plantas superiores como helechos (Pteris vittata), frescura (Pilea microphylla), plantas inferiores como los musgos, entre otras. Este deterioro se debió en gran medida a la pérdida paulatina de los elementos de carpintería y el desplome de la cubierta, lo cual fue propiciando la entrada de agua y la deposición de elementos biológicos en un espacio confinado, que culminó en la formación de un micro ambiente en el interior el teatro.

Como ha sido comentado, desde el punto de vista estructural, estos procesos determinaron la vida de servicio hasta un punto crítico, en el cual la obra se encuentra actualmente en elevado riesgo de derrumbe, con la consiguiente significación de pérdida de la obra construida. En las Figuras 3-5, se presentan identificados en color rojo, aquellos elementos estructurales que requieren de una intervención inmediata.
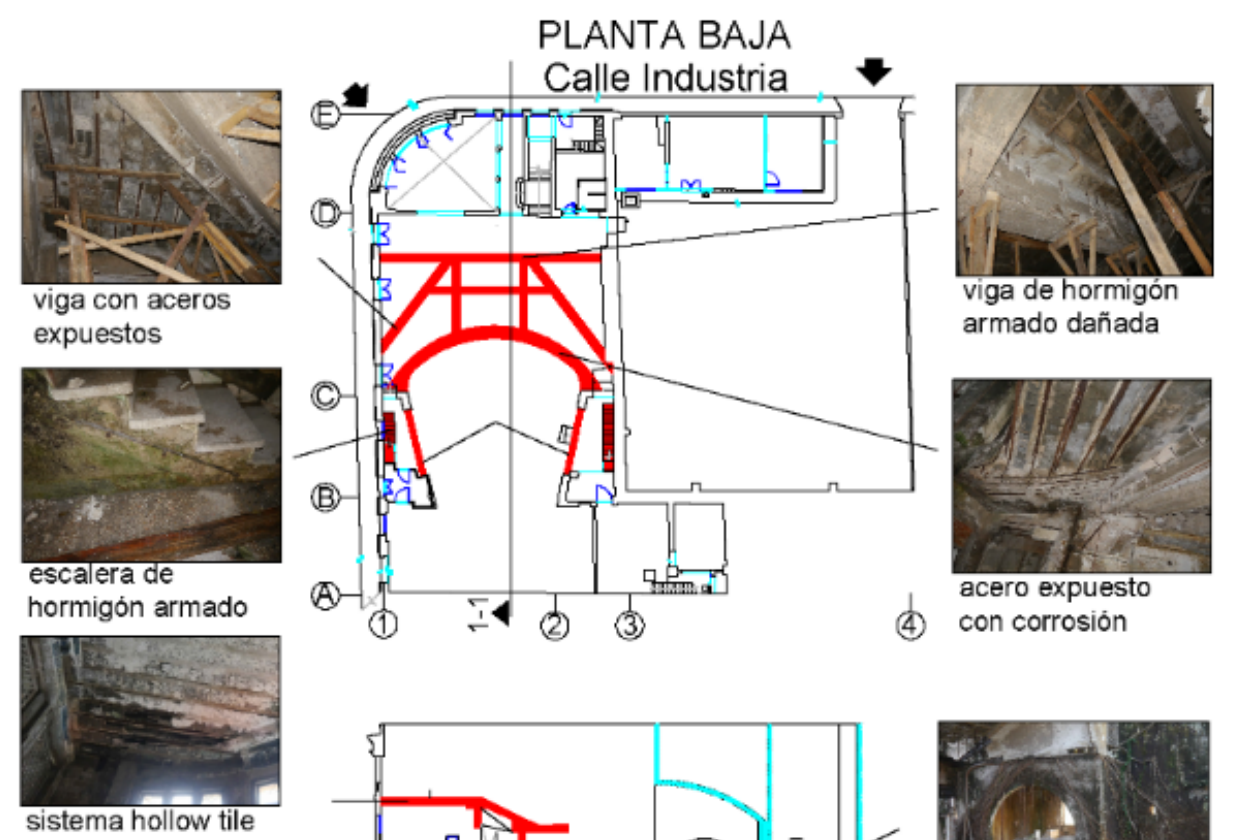
dañado

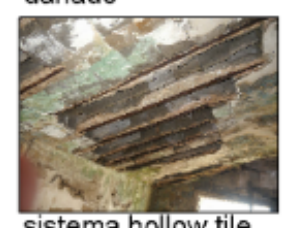

con pérdida de sección

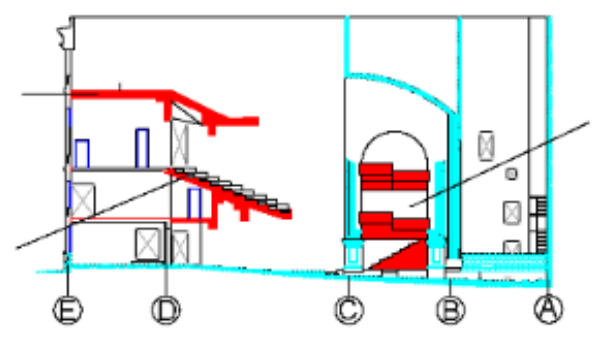

CORTE 1-1

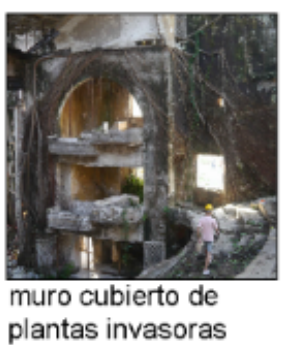

plantas invasoras

Figura 3. Deterioro avanzado de daños por corrosión en las vigas de hormigón armado, los aceros del sistema hollow tile y los refuerzos de las escaleras. Los muros interiores se muestran colonizados por raíces y musgos. 


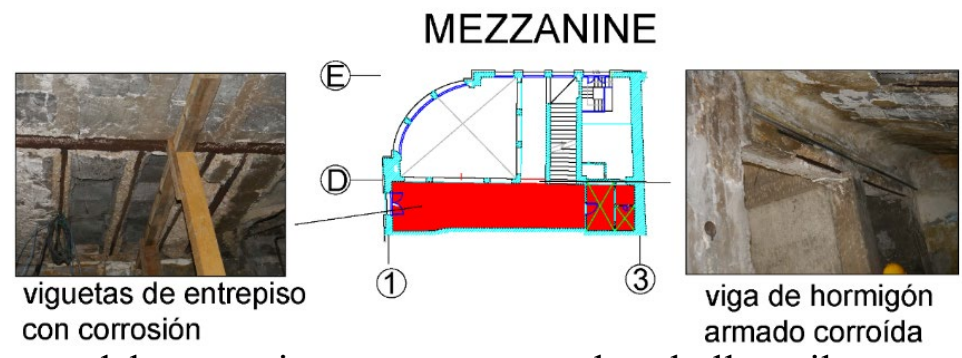

Figura 4. Estructura del mezzanine compuesta por losa hollow tile apoyada sobre viga de hormigón armado, severamente afectada por fenómenos de corrosión atmosférica.

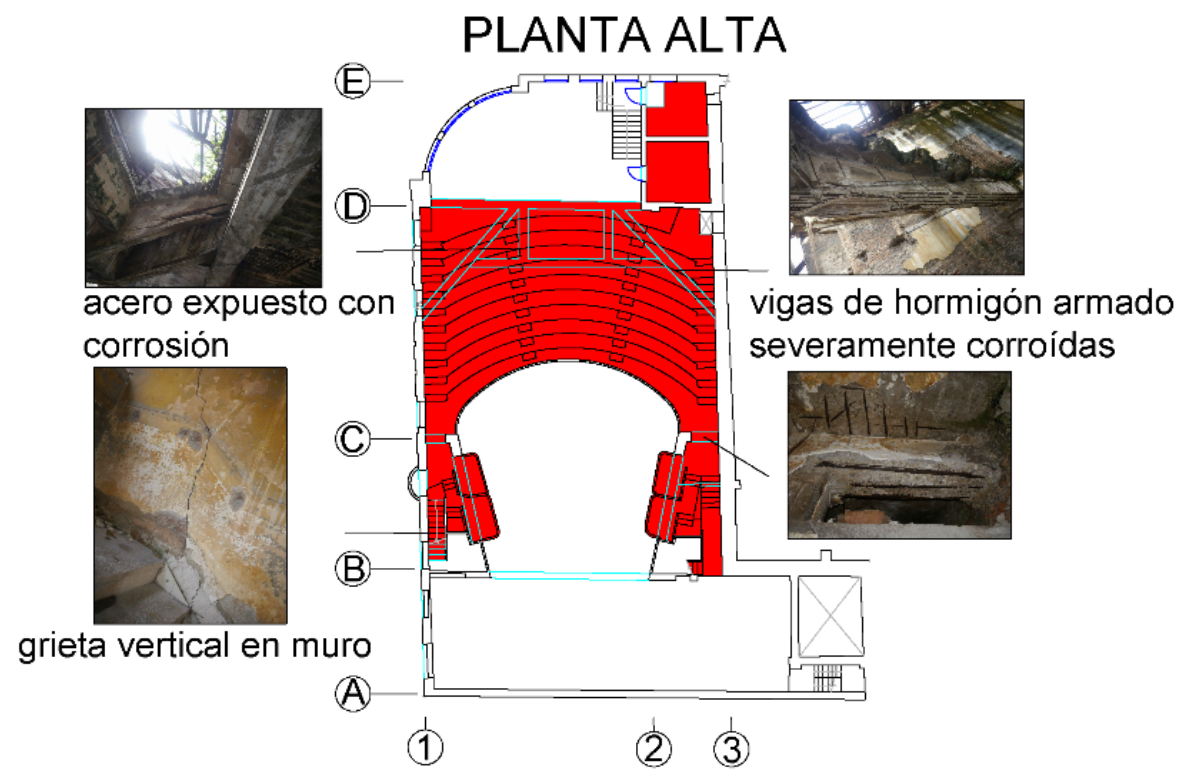

Figura 5. Planta alta del teatro en el sistema de soporte de la platea y los balcones, con grietas verticales en los muros y pérdida total del recubrimiento con refuerzos de acero corroídos.

\subsection{Evaluación del estado de conservación de las fachadas}

\subsubsection{Deterioros presentes en los muros}

Las fachadas están conformadas por un sistema porticado de columnas y vigas de hormigón armado, enchapadas con ladrillos colocados a citara en el planta baja y alicatados en el resto de los niveles. En el muro de fachada, conformado por un semicírculo entre las calles Industria y San José, los espacios entre columnas están cerrados por ladrillos colocados de forma alicatada. Los elementos de soporte estructural, muestran afectaciones por corrosión de los refuerzos de acero. Las barras colocadas presentan tres tipos de geometría: redondas corrugadas, cuadradas torcidas y cuadradas simples. En sentido general, las cuadradas torcidas y las redondas corrugadas fueron colocadas en las columnas, mientras las cuadradas simples están en las vigas y dinteles.

Las mayores afectaciones por corrosión se localizan en la fachada semicircular (entrada principal al teatro). Las barras están prácticamente expuestas, algunas han perdido continuidad y el hormigón remanente está agrietado y disgregado. De forma similar sucede con las vigas y dinteles, en donde igualmente por corrosión, el hormigón se ha desprendido y las barras se encuentran expuestas. Existen zonas que, como resultado de los movimientos mecánicos entre los materiales, muestran abofamientos muy pronunciados con riesgo de desprendimiento, fundamentalmente en elementos decorativos del muro semicircular.

Se identificó una grieta inclinada en la fachada hacia la calle San José que puede estar asociada a movimientos de acomodamiento que ha sufrido la estructura por envejecimiento de los materiales, 
al ataque de plantas invasoras de porte arbóreo, a la ausencia de viga de cierre o a la combinación de varios de estos factores.

El enchape de ladrillos, fundamentalmente en la base y hacia la calle San José, se encuentra muy socavado y con textura arenisca. Por lo general este tipo de lesión es debida a cocidos ineficientes durante su conformación en los hornos, lo cual deja partículas higroscópicas que se expanden con el incremento de la humedad durante la noche, o en días de lluvias. Al cesar este proceso el material pierde la humedad producto del calor del día, y como resultado se generan procesos cíclicos de expansión y dilatación que culminan con el ablandamiento y desprendimiento del material. De esta manera también se pierde el mortero de repello, lo cual deja expuesto el ladrillo a una mayor exposición de las condiciones climáticas.

Como resultado de la exposición a emisiones por fuente móviles, en casi toda la extensión de los muros, se han formado costras negras, las cuales tienen una mayor concentración en las zonas muertas como bajo balcones y aleros, debido a que quedan protegidos de las lluvias y el sol. En las Figuras 6 y 7 se muestra una representación de los deterioros que afectan las fachadas.
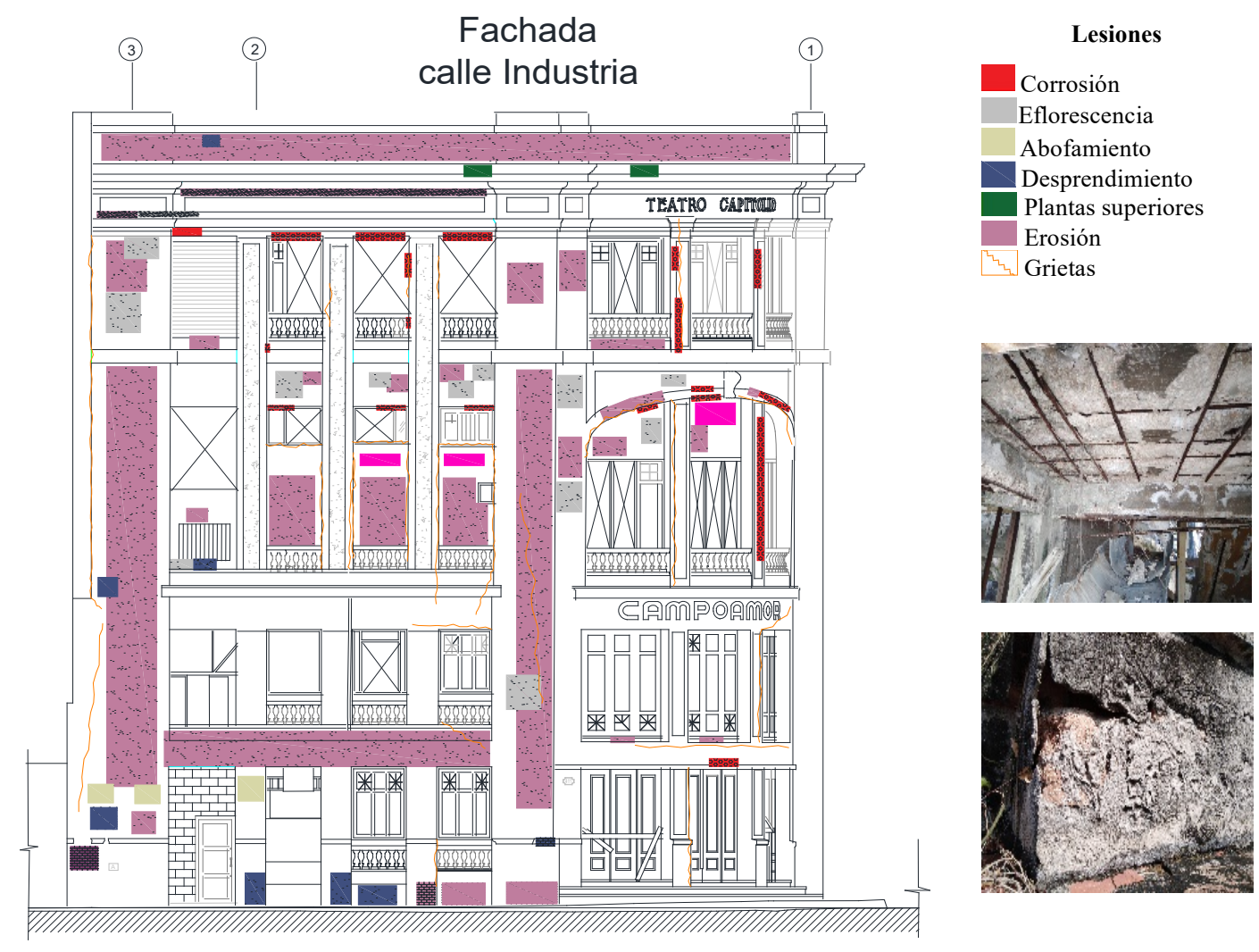

Figura 6. Degradación de los materiales en la fachada hacia la calle Industria. 


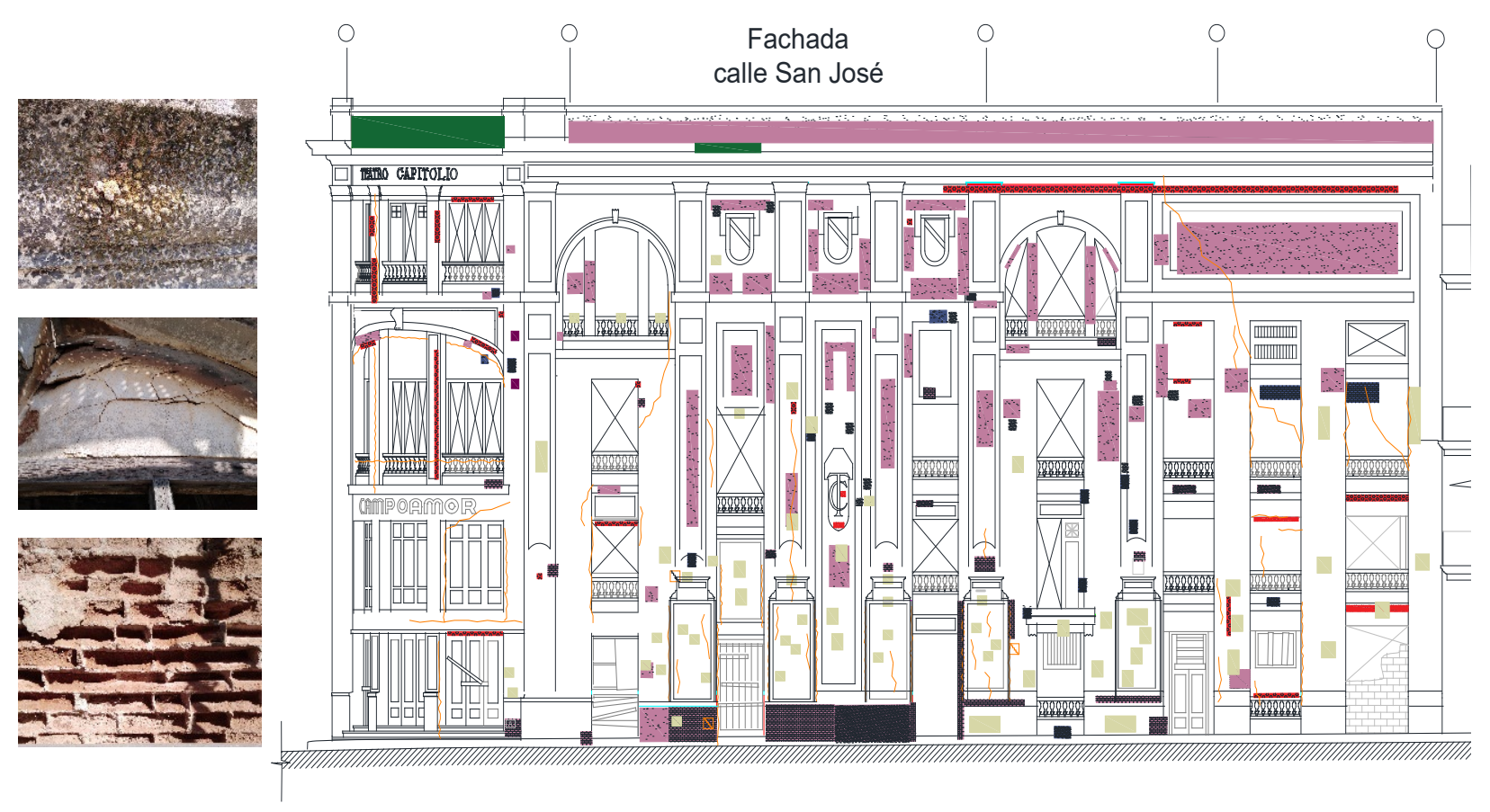

Fig. 7. Degradación de los materiales en la fachada hacia la calle San José.

\subsubsection{Relación de deterioros y niveles de impacto}

En la evaluación de lesiones y sus niveles de impacto en la estructura se tienen en cuenta factores basados en la presencia o ausencia de elementos, magnitud de la degradación de los materiales y el estado estructural, basado en su estabilidad y riesgo de deformación por las cargas actuantes. Adicionalmente deben considerarse las condiciones climáticas y su nivel de influencia en los diferentes materiales presentes (ladrillo, hormigón, madera, acero). En la Tabla 1 se muestran los resultados del análisis realizado a partir de los resultados obtenidos en la evaluación de lesiones. Los deterioros existentes como resultados de la formación de grietas, desprendimiento y pérdida de material, son los que más impacto tienen en el teatro. En consecuencia, existe un elevado riesgo de colapso de la estructura, por lo que se requiere un proyecto inmediato de apuntalamiento y reforzamiento, seguida de un estudio diagnóstico profundo y un proyecto de restauración que lo devuelva, en la medida de lo posible, a su estado original.

\subsubsection{Análisis de verticalidad de los muros de fachada}

Un aspecto importante a considerar en cuanto a la estabilidad estructural del inmueble es la verticalidad de las fachadas. Puesto que se trata de una edificación en donde el sistema constructivo se basa en el apoyo de casi toda la estructura interior en los muros de fachada, la amplia variedad y diversidad de daños presentes suponen un riesgo para todo el inmueble. Durante la inspección se identificaron grietas que pueden estar asociados a movimientos en los elementos de fachada. Debido a esto se generaron modelos de elevación a partir de las imágenes obtenidas mediante el empleo del escáner láser Z+F Imager ${ }^{\circledR} 5010$ c. Los modelos de elevación se basan en imágenes que mediante una escala color previamente definida, permiten identificar si existen diferencias entre la cima y la base del elemento vertical escaneado. Los valores positivos hacen referencia a movimientos hacia el frente o a elementos que no están en la línea de fachada (puede ser el caso de elementos estructurales con diferentes secciones o elementos decorativos), y los valores negativos hacen referencia movimientos hacia el fondo (carpintería, diferencia en la sección de los elementos, etc.). El análisis se realizó en la fachada hacia la calle Industria (Figura 8) y la fachada 
hacia la calle San José (Figura 9). En el caso de la fachada semicircular (entrada principal), el modelo obtenido no permite análisis similar porque su forma no es recta. En todos los casos se definió como el cero de referencia, el eje central en sentido horizontal. Las unidades se expresan en mm y las magnitudes indican las diferencias con respecto al cero de referencia.

Tabla 1. Relación de degradación de los materiales y su nivel de impacto en la estructura.

\begin{tabular}{|c|c|c|c|c|c|}
\hline & $\begin{array}{c}\text { Grietas y } \\
\text { deformaciones }\end{array}$ & Desprendimiento & $\begin{array}{l}\text { Pérdida } \\
\text { de } \\
\text { material }\end{array}$ & $\begin{array}{l}\text { Decoloración } \\
\text { y depósito }\end{array}$ & $\begin{array}{c}\text { Colonización } \\
\text { biológica }\end{array}$ \\
\hline $\begin{array}{l}\text { Fachada } \\
\text { San José }\end{array}$ & $\begin{array}{l}\sqrt{ } \\
3 \\
\end{array}$ & 2 & 2 & 3 & 3 \\
\hline $\begin{array}{l}\text { Fachada } \\
\text { Industria }\end{array}$ & 1 & 1 & 1 & 2 & 1 \\
\hline $\begin{array}{l}\text { Fachada } \\
\text { (entrada) }\end{array}$ & $\sqrt{ }$ & 3 & 3 & 3 & 0 \\
\hline Mezzanine & 1 & 3 & 3 & 0 & 3 \\
\hline Balcones & 1 & 2 & 2 & 1 & 3 \\
\hline Escaleras & 1 & 2 & 2 & 0 & 1 \\
\hline Carpintería & 3 & 3 & 3 & 2 & 0 \\
\hline Losas & 3 & 3 & 3 & 0 & $\begin{array}{l}\checkmark \\
0\end{array}$ \\
\hline Cubierta & & & xistente & & \\
\hline
\end{tabular}

El análisis de las fachadas muestra homogeneidad en el color, sin existir variaciones significativas, lo que sugiere que actualmente no hay pérdida de verticalidad. Con los resultados obtenidos se infiere que la aparición de las grietas inclinadas es el resultado del acomodamiento que ha sufrido la edificación debido al envejecimiento de los materiales y al ataque de plantas invasoras de porte arbóreo. Los colores obtenidos en los balcones y los balaustres son de un tono amarillo y rojo porque corresponden a elementos que se encuentran más profundos que el muro de la fachada por lo cual, de acuerdo a la escala empleada, estos se muestran en valores negativos. Lo mismo ocurre con los aleros y decoraciones donde los colores obtenidos están entre azul claro y azul oscuro, porque hace referencia a valores positivos. 


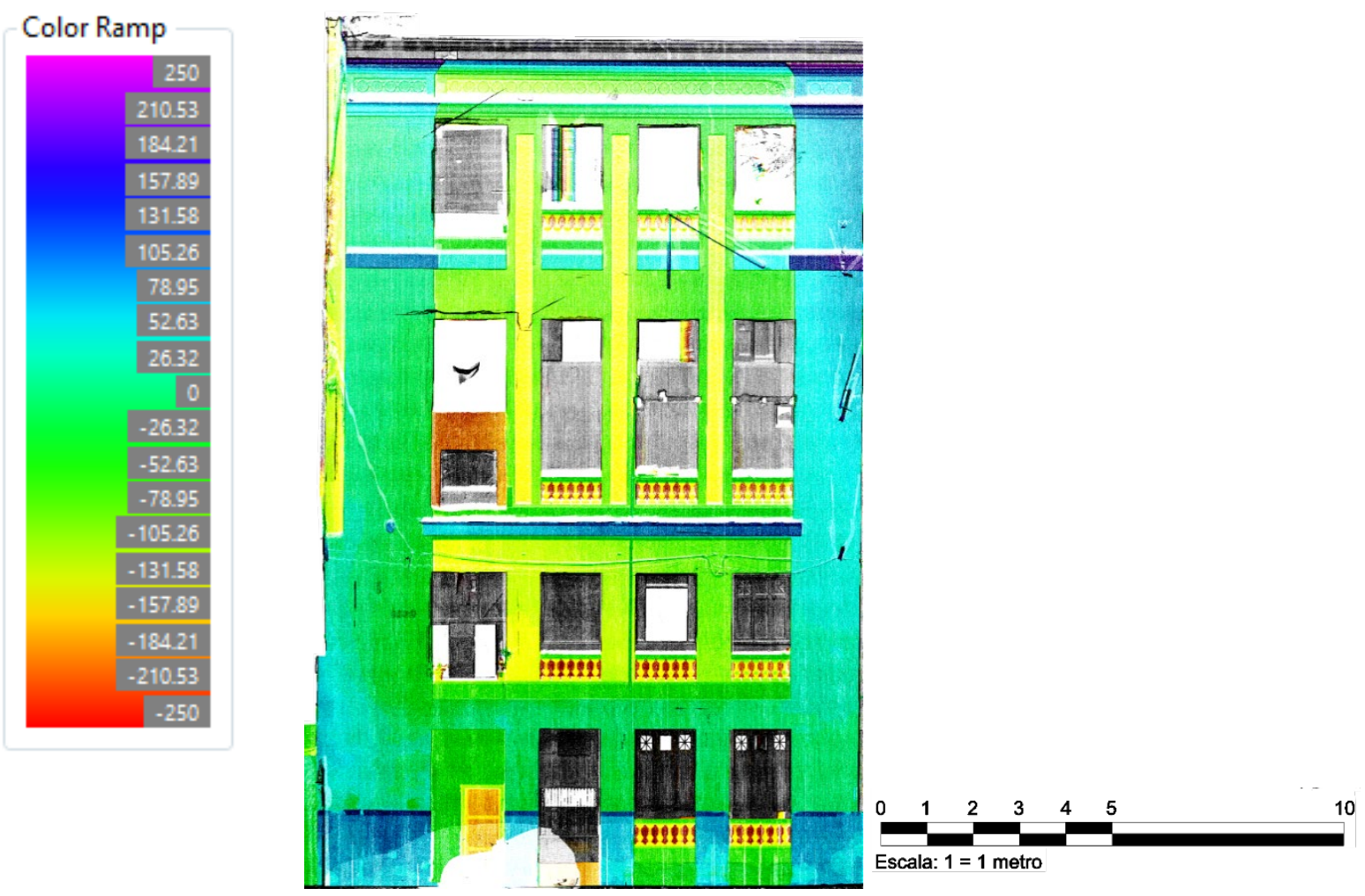

Figura 8. Modelo de elevación de la fachada hacia la calle Industria.

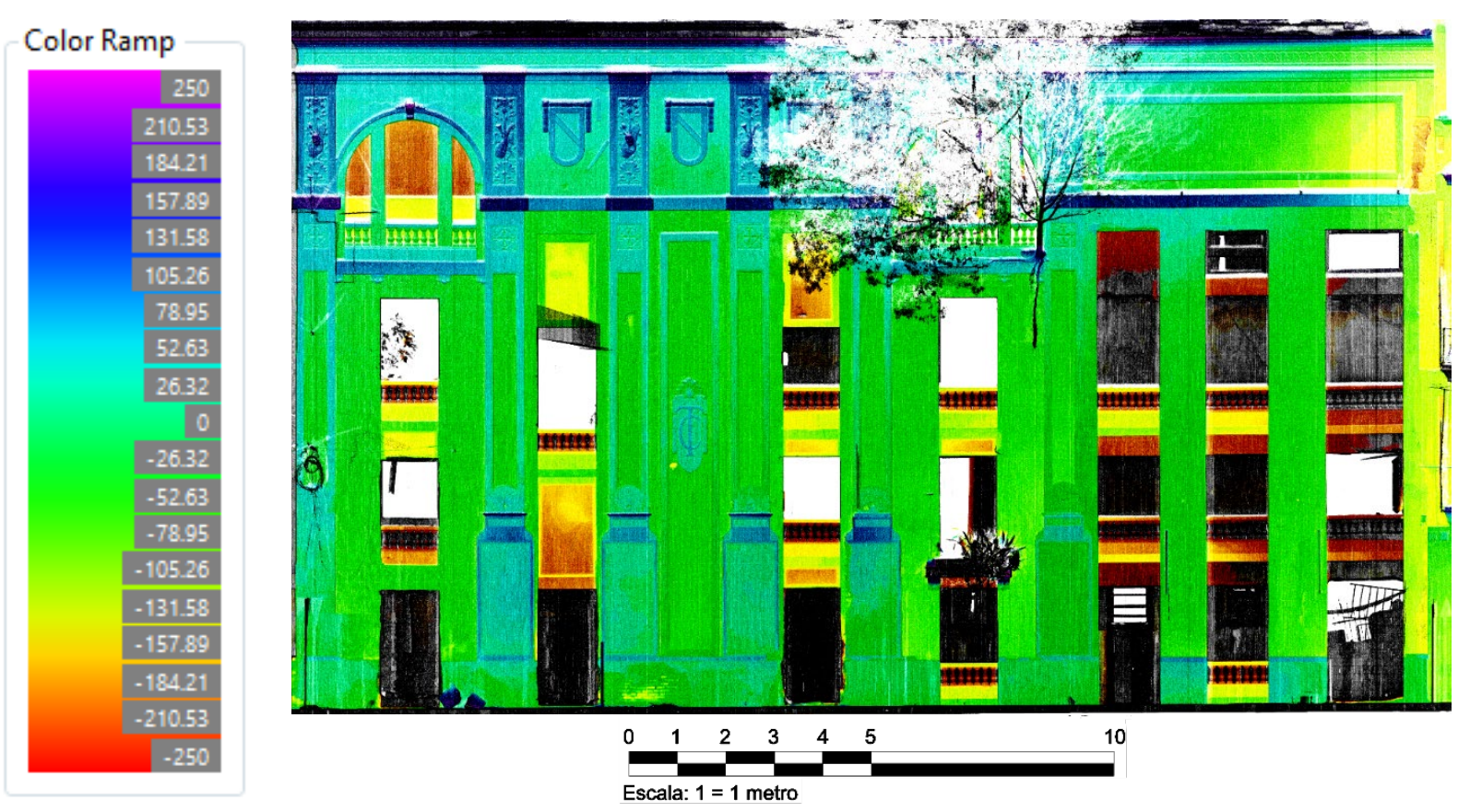

Figura 9. Modelo de elevación de la fachada hacia la calle San José. 


\section{CONCLUSIONES}

En el presente trabajo se mostraron los resultados obtenidos de la evaluación realizada al teatro Campoamor, en donde se registraron todas las lesiones presentes y su nivel de impacto en la estabilidad de la estructura.

La pérdida de la cubierta y la carpintería de las fachadas facilitaron la entrada de agua pluvial, lo cual propició la formación de un micro ambiente húmedo en el interior que desencadenó una serie de procesos patológicos devenidos en colonización de plantas y microorganismos, corrosión del refuerzo, delaminación de los perfiles, pérdida de sección de las barras de acero, desprendimiento y formación de grietas verticales e inclinadas.

Los muros de fachada son de los elementos más comprometidos debido al elevado nivel de degradación de los materiales como resultado de la interacción de diversos factores estructurales, antropogénicos y ambientales. Esta combinación de elementos genera mecanismos muy complejos de deterioros, que después de décadas de abandono, es difícil atribuir el origen del deterioro a una sola fuente. Sin embargo, a pesar de la magnitud y severidad de lesiones que muestran, los modelos de elevación obtenidos, no reflejan pérdida de la verticalidad.

Para evitar el colapso de la estructura, se requieren de acciones inmediatas de reforzamiento y apuntalamiento, para iniciar el proceso de rehabilitación y reutilización del teatro.

\section{AGRADECIMIENTOS}

El presente trabajo se realizó bajo el Proyecto de Restauración del Teatro Campoamor a cargo de la Entidad Inversionista Obispo de la Oficina del Historiador de La Habana. Los autores desean agradecer el apoyo prestado por todo el equipo de trabajo de esta entidad.

De igual manera, se desea agradecer al Ing. Rafael González por su experiencia en los sistemas constructivos y sus mecanismos de deterioro, así como al Lic. Pedro R. Cuétara por su ayuda en la creación de orto-imágenes y modelos de elevación a partir del escáner láser.

\section{REFERENCIAS}

Brimblecombe, P., Grossi, C.M. and Harris, I., 2011. Climate change critical to cultural heritage, Survival and sustainability. Springer, pp. 195-205.

Cavalagli, N., Kita, A., Castaldo, V., Pisello, A. and Ubertini, F., (2019), Hierarchical environmental risk mapping of material degradation in historic masonry buildings: An integrated approach considering climate change and structural damage. Construction and Building Materials, 215: 998-1014. https://doi.org/10.1016/j.conbuildmat.2019.04.204

Di Turo, F., Proietti, C., Screpanti, A., M. Francesca Fornasier, Cionni, I., Favero, G. and Marco, A.D., (2016), Impacts of air pollution on cultural heritage corrosion at European level: What has been achieved and what are the future scenarios. Environmental Pollution: 1-9. http://dx.doi.org/10.1016/j.envpol.2016.07.042

Fowler, D., Brimblecombe, P., Burrows, J., Heal, M.R., Grennfelt, P., Stevenson, D.S., Jowett, A., Nemitz, E., Coyle, M. and Lui, X., (2020), A chronology of global air quality. Philosophical Transactions of the Royal Society A, 378(2183): 20190314. http://dx.doi.org/10.1098/rsta.2019.0314 
ICOMOS-ISCS, (2008), "Illustrated glossary on stone deterioration patterns, monuments and sites".

IPCC, 2014. Climate Change 2014: Impacts, Adaptation, and Vulnerability.

ISO-9223. (2012). Corrosion of metals and alloys. Corrosivity of atmospheres. Classification, determination and estimation.

Kumar, P. and Imam, B., (2013), Footprints of air pollution and changing environment on the sustainability of built infrastructure. Science of The Total Environment, 444: 85-101. http://dx.doi.org/10.1016/j.scitotenv.2012.11.056

Oroza, A.H., (2019), Impact of environmental pollution in the historical buildings of Havana. Effect of future climate change. Revista Ingeniería de Construcción, 33(3): 219-228. http://dx.doi.org/10.4067/S0718-50732018000300219

Paradiso, M., Garuglieri, S. and Ferrarini, V., (2020), The Convent of Santa Teresa de Jesús in Havana: analysis, consolidation and restoration for the New Museum of Sacred Art. Procedia Structural Integrity, 29: 87-94. http://doi.org/10.1016/j.prostr.2020.11.143

Placeres, M.R., Bermejo, P.M., Lacasaña-Navarro, M., Rojo-Solís, M.M.T., Aguilar-Valdés, J. and Romieu, I., (2004), Contaminación atmosférica, asma bronquial e infecciones respiratorias agudas en menores de edad, de La Habana. Salud Pública de México, 46(3): 222-233.

Sánchez, Z.I., 2017. Historia del Teatro Campoamor, Empresa de Proyectos. Restaura, Oficina del Historiador de La Habana.

Varona, M.M., Maldonado, G., Esquivel, E.M. and Fernández, A., (2011), Daily changes of air pollutant levels in Havana (CUBA). Higiene y Sanidad Ambiental, 11: 786-792. 